\title{
Experiencia de los principios morales: Kant y Tomás de Aquino
}

\author{
MARÍA ELTON \\ Universidad de los Andes (Chile) \\ melton@uandes.cl
}

\begin{abstract}
Resumen
En la tradición ilustrada de Kant y en la tradición aristotélica de Tomás de Aquino encontramos los mismos elementos para explicar la experiencia moral: razón práctica del hombre común, ley moral, voluntad, inclinaciones naturales. Pero la relación de estos elementos entre sí varía radicalmente de una tradición a otra, ya que en la tradición kantiana la razón práctica y la ley moral son completamente heterogéneas respecto a las inclinaciones naturales. En la tradición aristotélica de Tomás de Aquino, en cambio, la razón práctica que conoce la ley moral es parte de la naturaleza del hombre. En la tradición kantiana la ética se encuentra completamente separada de la antropología, y no se conoce a partir de la experiencia. En la tradición aristotélico-tomista, la ética se conoce a partir de la experiencia y su conocimiento es explicable a partir de ella.
\end{abstract}

Palabras clave: Razón práctica, ley moral, voluntad, inclinaciones, antropología.

\section{Experience of moral principles: Kant and Thomas Aquinas}

\begin{abstract}
Both Kant's Enlightenment tradition and Aquinas' Aristotelian tradition will usually manage the same elements in order to explain the reality of moral experience, namely: practical reason of the common man, moral law, will, and natural inclinations. Yet the relation existing between these elements certainly varies from one tradition to the other since, within Kantian tradition, practical reason and moral law are completely heterogeneous with regard to natural inclinations. On the contrary, within Aquinas' Aristotelian tradition, the same practical reason that recognizes the moral law is itself an element of human nature as well. Thus, according to Kantian tradition, ethics are totally detached from anthropology, and they are not grasped out of experience. Aristotelian-Thomistic tradition would state that ethics are grasped through experience and, although they are certainly not derived from anthropology, this later would make the grasping of the former explicable.
\end{abstract}

Key words: Practical reason, moral law, will, inclinations, anthropology.

Profesora Titular del Instituto de Filosofía de la Universidad de los Andes. Es autora de cinco libros y variados artículos en revistas especializadas sobre temas de filosofía moral clásica e ilustrada. Por su relación con este artículo cabe destacar dos publicaciones recientes: Moral Science and Practical Reason in Thomas Aquinas (2013) y "La "heteronomía' de la voluntad kantiana: una comparación con Tomás de Aquino” (2013). 


\section{Introducción}

El rigorismo y el formalismo de la filosofía moral kantiana, junto al desprecio de los sentimientos morales espontáneos que lleva consigo, despertó un fuerte rechazo entre los mismos amigos de Kant y entre pensadores importantes contemporáneos suyos e inmediatamente posteriores, que lo criticaron abiertamente. Entre estos últimos destacan Schiller, Hegel y Schopenhauer (Delbos, 1969: 264-268). Esa crítica ha sido $\tan$ fuerte e influyente que el neokantismo ha intentado una reinterpretación de la filosofía moral kantiana que supere el formalismo en cuestión (González, 2003: 776-779).

Por otra parte, la ética kantiana ha sido recibida muy favorablemente en amplios sectores de la cultura, debido a que Kant percibió con profundidad la necesidad de basar la vida moral en un motivo supremo y desinteresado, propio de la razón, libre de la supremacía del amor de sí (Maritain, 1995: 406). Sin embargo se trata de una razón que no es natural y no precede a su propio pensamiento moral, sino que se reduce a la espontaneidad de la ley moral universal cuando juzga la legitimidad o ilegitimidad moral de las máximas que se propone el individuo. Según los presupuestos kantianos es imposible reconocer la dimensión natural del espíritu humano y de fenómenos morales tales como las inclinaciones naturales o la tendencia natural de la voluntad al bien. La naturaleza no es más que la legalidad de los fenómenos espacio-temporales, la cual, en el caso del hombre, se encuentra yuxtapuesta al espíritu (Rodríguez Luño, 2004: 70-79). Ciertamente Kant, en su período pre-crítico, fue influido por el empirismo moral escocés (Kant, 1968: 298-300 y 311-12), y conservó alguno de sus rasgos fundamentales en su período crítico (Edwards, 2000; Edwards \& Brook, 2000), pero rechazando categóricamente todo intento de fundamentar la moralidad en las inclinaciones naturales sensibles del hombre. La ley moral no tiene, según Kant, una validez moral limitada a los hombres, sino que vale para todos los seres racionales (Kant, 1968: 389), para los seres racionales en general, sin ninguna dependencia ni de la naturaleza ni de la antropología (Kant, 1968: 411). La naturaleza humana es sólo naturaleza empírica, a partir de cuyas inclinaciones sensibles el hombre se propone máximas que deben ser contrastadas con los dictámenes de la razón pura práctica a priori.

El racionalismo moral kantiano se manifiesta, entre otras cosas, en que sitúa la solución al debate moral fuera del tiempo (Kant, 1968: 31, 66 y 70), en la razón pura a priori, que se encuentra más allá y es completamente independiente del tiempo, concebido por Kant como una categoría de la sensibilidad que ordena los fenómenos conocidos por la experiencia. La razón pura a priori determina el carácter moral obligatorio de 
ciertas acciones del hombre, el cual no se deriva de las propiedades particulares de la naturaleza humana, tales como ciertos sentimientos, o tendencias, o alguna dirección especial de la razón humana que no tenga un valor necesario, y se derive con una necesidad práctico-incondicionada para la voluntad de todo ser racional (Kant, 1968: 425). La ley moral de la razón pura a priori, al determinar los valores morales, crea una segunda naturaleza en el hombre, su «naturaleza racional» (Kant, 1968: 435-6), que tiene autonomía total respecto a la naturaleza humana empírica.

Como ha dicho MacIntyre:

en la filosofía de Kant hay dos tesis centrales engañosamente sencillas: si las reglas de la moral son racionales, deben ser las mismas para cualquier ser racional, tal como lo son las reglas de la aritmética; y si las reglas de la moral obligan a todo ser racional, no importa la capacidad de tal ser para llevarlas a cabo, sino la voluntad de hacerlo. El proyecto de descubrir una justificación racional de la moral es simplemente el de descubrir una prueba racional que discrimine, entre diversas máximas, cuáles son expresión auténtica de la ley moral, al determinar a qué voluntad obedecen aquellas máximas que no sean tal expresión (MacIntyre, 1987: 65).

Esa doble acusación encierra dos grandes problemas de la filosofía moral kantiana que me propongo analizar en la próxima sección: por una parte la justificación racional de la moral no es más que eso, justificación racional como la de la aritmética, porque prescinde de las tendencias del hombre como principios morales, reduciendo de paso toda inclinación humana sólo a inclinación sensible. Por otra parte, la naturaleza sensible del hombre no se encuentra capacitada para seguir las máximas aprobadas por la ley moral, por lo que debe ser obligada a la fuerza.

A pesar de que Kant buscó un principio incondicionado de la moral, su propia filosofía moral adolece de ciertos condicionamientos que hacen conveniente ponerla en discusión con la filosofía moral de Tomás de Aquino. Para explicar esos condicionamientos quiero hacer una distinción entre la justificación racional de la moral que, como veremos, es en Kant una tarea del hombre común; y la fundamentación filosófica que hace Kant de esa tarea común y cotidiana. Si la primera - la justificación de la moral-, es atemporal e incondicionada según los presupuestos filosóficos de Kant, para quien el tiempo es sólo una categoría de la sensibilidad; la segunda - la fundamentación filosófica de la racionalidad moral- está fuertemente condicionada por ciertos presupuestos históricos y metodológicos que hacen presa del filósofo de Könisberg precisamente en su labor de criticarlos. 
Uno de los grandes aciertos de la filosofía moral kantiana es haber recuperado para la ética su carácter práctico y su asiento en la razón práctica, lo cual se había perdido con el racionalismo voluntarista que predomina de distintas maneras, con distintos énfasis y matices, desde el iusnaturalismo de la escolástica posterior a Tomás de Aquino hasta Wolff, antecesor inmediato de Kant (González, 1999: 5-23). Pero si bien Kant logró desprenderse del racionalismo de Wolff para explicar la ética, no se desprendió del todo, sin embargo, del empirismo también predominante en su época, que asume no como explicación de la moralidad de las acciones, sino como interpretación antropológica de la naturaleza humana, la cual, así entendida, no puede fundamentar la ética, estableciéndose entonces una brecha entre antropología y ética, la cual está en el origen de su formalismo. Por otra parte deja atrás definitivamente, aunque no intencionalmente, la armonía que existía entre antropología y ética en la filosofía aristotélico-tomista.

Me parece por tanto plenamente justificado recurrir a esa filosofía anterior para superar el problema del formalismo moral kantiano, en el cual Kant se vio envuelto por el encerramiento histórico y metodológico de su pensamiento. Como dice MacIntyre, para reconocer que un sistema filosófico y práctico está en disputa con el propio, se requiere la capacidad de traducir su idioma y sus términos dentro del propio, y también el reconocimiento de sus tesis, argumentos y procedimientos como susceptibles de juicio y evaluación por los mismos estándares que el propio. El mismo hecho de reconocer puntos de vista rivales lleva consigo reconocer también, implícitamente, que esos puntos de vista han sido formulados desde el punto de vista de normas de inteligibilidad y evaluación comunes (MacIntyre, 1990: 5). Más todavía, la admisión de inconmensurabilidad e intraducibilidad en la relación entre dos sistemas opuestos de pensamiento filosófico y práctico puede ser el prólogo no sólo para el debate racional, sino también para un tipo de debate en que una parte surge con una racionalidad indudablemente superior a la otra, porque el debate manifiesta que uno de los sistemas en contienda falla en sus propios términos, debido a sus propios estándares (MacIntyre, 1990: $5)$.

Con cierta frecuencia se ha establecido un debate entre la filosofía moral kantiana, por un lado, y la filosofía moral de Platón y/o Aristóteles y/o los estoicos por otro (González, 2003: 777-778). Pero lo que se ha evitado es establecer un debate entre Kant y la filosofía cristiana medieval, en concreto entre Kant y Tomás de Aquino. Algunos piensan que la razón moral tomasiana no es autónoma como la de Kant (Schneewind, 1998: 21), por lo que un debate entre ambos puntos de vista no tendría lugar en un terreno homogéneo. Como decíamos en el párrafo anterior, 
para que haya debate entre dos sistemas filosóficos tiene que haber cierto acuerdo fundamental a partir del cual discutir y enriquecer la teoría rival. Ahora bien, me parece que afirmar que la razón moral tomasiana no es autónoma, como lo hace Schneewind, es un error basado en un concepto sesgado de autonomía. El tema puede ser analizado con toda su amplitud en otro artículo, por lo que no me corresponde abordarlo aquí. Basta por ahora afirmar que en Tomás de Aquino se encuentra una concepción de la autonomía moral de la persona más rica que la de Kant en algunos aspectos. Es la que Rhonheimer, utilizando un término tomado de la sociología actual, ha denominado «autonomía personal», la cual se explica porque el concepto tomista de acto bumano manifiesta la capacidad de dominio que el hombre tiene sobre sus propios actos, y la libertad con que la voluntad puede decidir sobre ellos (Aquino, 2006: II, 39-40; Aquino, 2001: 121-123; Rhonheimer, 2000a: 197-200).

Por otra parte, entre Kant y Tomás de Aquino se puede establecer un acuerdo fundamental a partir del cual comenzar el debate: la ley moral tiene su origen en la razón práctica de la persona común. En Aristóteles y Tomás de Aquino, la moral no se nos presenta a partir de una fundamentación teórica de ciertas normas ideales, sino a partir de la razón práctica, que introduce orden en ciertos deseos y tendencias de nuestra naturaleza (Aquino, 2000a: 9-14, 16-17, 17-19). La razón práctica, a su vez, sólo puede realizar su función directiva si el dinamismo tendencial se encuentra mínimamente enderezado, es decir si hay virtud moral, por lo que la moral tiene su origen tanto en la razón como en la naturaleza entendida como tendencia (González, 1999: 8-9). Tomás de Aquino asume este esquema aristotélico, y le añade la voluntad natural que unifica la multiplicidad de tendencias y apetitos de la psicología humana (Tomás de Aquino, 2006: 132-133), la cual es iluminada y guiada por el intelecto (Tomás de Aquino, 2006: 73). En el intelecto se encuentra, a su vez, según Tomás, un hábito intelectual práctico, la sindéresis (Aquino, 2006: I, 737-738); Tomás de Aquino, 1998: 33-52), el cual permite plantear la cuestión de los preceptos morales universales, que no se encuentra resuelta en Aristóteles, y es coherente con la universalidad de la fe cristiana y la comunidad de naturaleza existente entre los hombres. No se trata por cierto de un planteamiento naturalista, porque el conocimiento de los preceptos morales no se cimenta en la sola naturaleza entendida como una conjunto de tendencias, sino más bien en la naturaleza de la razón práctica, de la cual encontramos en Tomás un planteamiento de enorme interés (González, 1999: 9-11).

Con el amplio desarrollo del iusnaturalismo moderno en las universidades europeas a lo largo de los siglos XVI y XVII, se perdió ese concepto de razón práctica, hasta el punto de considerarse el precepto mo- 
ral, que es el acto específico de la razón en su función práctica, como un simple resultado de añadir voluntad a un conocimiento teórico. La forma del precepto es, en este planteamiento, algo extrínseco al agente, es decir algo que Kant denominaría heteronomía. El déficit fue heredado por la ética racionalista, contra la cual reacciona críticamente Kant (González, 1999: 11). Esta última intenta deducir los preceptos morales a partir de premisas teóricas, lo cual fue criticado por el empirismo de Hutcheson y Hume, para quienes ese tipo de juicios morales derivados de juicios teóricos no son prescriptivos, añadiendo que, para serlo, tienen que provenir del sentido moral o del sentimiento moral. Pues bien, Kant pretende salvar la capacidad prescriptiva de la razón contra el empirismo, en su función práctica, evitando al mismo tiempo que esta sea contaminada por motivos provenientes de las inclinaciones sensibles contingentes, porque la ley moral debe ser universal (González, 1999: 13-34). Así cae en un formalismo que adolece de un déficit antropológico.

En definitiva, algo que debemos discutir a partir de Kant es la relación entre antropología y ética, es decir si los principios de la ética tienen o no su origen en elementos antropológicos, y si la razón práctica es parte de esa antropología o tiene una función independiente y meramente constrictiva de las tendencias del hombre. Para ello dividiré lo que queda de este escrito en tres secciones: la primera versará sobre la relación que establece Kant entre las inclinaciones sensibles y la razón pura práctica en relación a los principios de la moral; la segunda tratará de esa misma relación respecto a los principios morales en Aristóteles y Tomás de Aquino, haciendo algunas comparaciones con Kant; y la tercera sobre algunos aspectos antropológicos que fundamentan ambas visiones de la ética.

\section{La relación entre las inclinaciones sensibles y la razón pura prác- tica en Kant: los principios del deber moral}

Maritain se refiere a la defensa que hace Paton de la ética kantiana contra las objeciones de Schiller (Paton, 1948), afirmando que no es verdad que Kant haya enseñado que ninguna acción puede ser moral si tenemos alguna inclinación natural hacia ella, o si conseguimos con ella algo de placer. Considera sin embargo que Paton va demasiado lejos al afirmar que para Kant el amor de sí, el placer o la felicidad, pueden jugar un rol en la vida moral como motivos que actúan conjuntamente con la voluntad del deber por el deber. Piensa que la búsqueda de la felicidad, la consideración del placer o de la utilidad y el propio interés, el amor racional de sí mismo, pueden indudablemente jugar un rol en la materia de la moralidad, por ejemplo el cuidado de la propia salud, pero siempre a 
condición de que la única razón formal o motivación sea el deber, el respeto por la ley (Maritain, 1995: 407-8).

La ética kantiana ha sido conocida generalmente como una ética del deber. «El deber es», según Kant, «la necesidad de una acción por respeto a la ley» (Kant, 1968: 400). El conocimiento del deber compete a todos los hombres, incluso al más vulgar. No hace falta ni ciencia ni filosofía para saber qué es lo que se debe hacer para ser honrado y bueno y hasta sabio y virtuoso (Kant, 1968: 404). Los conceptos morales tienen su asiento en la razón humana más vulgar tanto como en la más altamente especulativa (Kant, 1968: 411). Conocer la ley moral y todas las acciones que manda no es, por tanto, para Kant, un esfuerzo teórico de deducción, sino una cuestión práctica, cuya dificultad no consiste en el conocimiento mismo, sino en el esfuerzo moral que lleva consigo. En efecto, no basta saber que unas determinadas acciones son deberes y otras son contrarias al deber, sino que ese conocimiento práctico tiene que ser enteramente racional, sin mezcla alguna de sensibilidad, lo cual lleva consigo una ascesis individual. Para que las acciones realizadas de acuerdo al deber sean realmente buenas moralmente, deben ser realizadas por deber, y no conformes al deber. Por ejemplo, conservar la propia vida es un deber, pero si yo la cuido por inclinación sensible, con angustia de perderla, estoy actuando conforme al deber y esa acción carece entonces de contenido moral. En cambio, si las adversidades me han arrebatado todo gusto por la vida y deseo la muerte, realizar ciertas acciones por conservar la vida es actuar por deber (Kant, 1968: 397-8), sólo por la ley, sin ninguna tendencia de la sensibilidad que me incline a vivir.

Kant establece una diferencia entre un hombre de buenas costumbres y un hombre moralmente bueno. El primero no tiene a la ley como motivo impulsor único y supremo de sus acciones, mientras que el segundo la tiene siempre. El primero actúa de acuerdo a la letra de la ley, mientras que el segundo actúa según su espíritu, que consiste en que sólo la ley es motivo impulsor suficiente. Cuando el albedrío es determinado a realizar acciones conformes al deber, son necesarios unos motivos impulsores distintos a la ley misma, tales como el apetito de honores, el amor a sí mismo en general, o incluso un instinto benévolo, como la compasión. Entonces la concordancia de los motivos con la ley es meramente contingente, porque igualmente podrían esos motivos empujar a la transgresión de la ley. En este último caso, la máxima según la cual el valor de la persona debe ser estimado es contraria a la ley, y el hombre que la asume para realizar sus acciones es malo, aunque realice acciones buenas (Kant, 1968: 30-1).

Para que las acciones se realicen por deber, el hombre debe pensar sus máximas como leyes prácticas universales válidas para todo ser ra- 
cional en general, que contengan el fundamento de determinación de la voluntad no en la materia de esos principios, sino en su forma. La materia es el objeto de la facultad de desear, cuya realidad es apetecida. Si el apetito hacia ese objeto precede a la regla práctica y es la condición para adoptarla como principio, ese principio es siempre empírico (Kant, 1968: 21-2), perteneciente al principio del amor a sí mismo o felicidad propia (Kant, 1968: 21), el cual, si determina a la voluntad, la somete a una condición empírica, a saber la relación de la representación determinante con el sentimiento de placer o dolor. Ahora bien, si de una ley se separa toda materia u objeto de la voluntad como fundamento de determinación, no queda más que la mera forma de una legislación universal (Kant, 1968: 27).

Para valer moralmente y ser fundamento de obligación moral, una ley tiene que llevar consigo una necesidad absoluta, que no se encuentra en la naturaleza humana, sino en la razón pura. Por ejemplo, el mandato «no debes mentir» vale para todos los seres racionales, y no sólo para el hombre, por lo que el fundamento de su obligación no puede encontrarse en la naturaleza del hombre (Kant, 1968: 389), la cual es parte de la Naturaleza en general, donde los fundamentos de determinación son los fenómenos según la ley de la causalidad (Kant, 1968: 28-9).

Para Kant no hay nada moralmente racional en la naturaleza del hombre. Al contrario, por una parte el hombre experimenta la naturaleza, esto es las inclinaciones cuya satisfacción total es la felicidad, como una fuerza poderosamente contraria a todos los mandamientos del deber; por otra parte, la razón ordena los preceptos del deber sin prometer nada a las inclinaciones, severamente, con desatención y desprecio de sus pretensiones impetuosas, que ningún mandamiento consigue nunca anular. De esta contraposición se origina una dialéctica natural en el hombre, esto es una tendencia a discutir las leyes del deber, a poner en duda su validez, o al menos su severidad estricta, a acomodar esos mandamientos a nuestros deseos y a nuestras inclinaciones privándoles de su dignidad, cosa que ni la misma razón práctica vulgar puede aprobar (Kant, 1968: 405).

Si bien el concepto de deber es sacado del uso vulgar de la razón práctica, no debe inferirse que Kant lo trate como concepto de experiencia. Al contrario, Kant considera que si frecuentemente conocemos, por experiencia, acciones realizadas en conformidad con el deber, siempre nos queda la duda si han ocurrido por deber, y si tienen por tanto valor moral (Kant, 1968: 406). La ley moral, como principio de toda naturaleza racional en general, no se conoce a partir de la experiencia (Kant, 1968: 430-1). La experiencia sólo manifiesta elementos empíricos pertenecientes al concepto de felicidad, es decir al bienestar (Kant, 1968: 418). «Los 
principios empíricos no sirven nunca para fundamento de las leyes morales», dice Kant. «Pues la universalidad con que deben valer para todos los seres racionales sin distinción, la necesidad práctica incondicionada que por ello les es atribuida desaparece cuando el fundamento de ella se deriva de la peculiar constitución de la naturaleza bumana o de las circunstancias contingentes en que se coloca» (Kant, 1968: 442).

Todos los principios prácticos que suponen una materia u objeto de la facultad de desear como fundamento de determinación de la voluntad, son empíricos y no proporcionan ninguna ley moral. Las leyes morales deben determinar la voluntad exclusivamente como voluntad, sin consideración de un efecto apetecido, siendo así categóricas, necesarias, independientes de condiciones patológicas, casualmente ligadas con la voluntad (Kant, 1968: 400). Un ser racional debe pensar sus máximas como leyes prácticas universales, es decir como principios que contengan el fundamento de determinación de la voluntad no según la materia, sino sólo según la forma. Si de una ley se separa toda materia u objeto de la voluntad como fundamento de determinación, sólo queda de esa ley la forma de una legislación universal según la cual se deben pensar las máximas subjetivas (Kant, 1968: 27).

Para hacer esa estricta separación entre principios empíricos provenientes de la naturaleza humana y principios morales puramente racionales, la persona tiene que realizar, según Kant, un esfuerzo en el cual consiste la virtud. Si quiere actuar moralmente, el hombre debe apartar todo objeto de la voluntad que, a sabiendas, produce placer (Kant, 1968: 225). Debe tener ante los ojos sólo la ley moral pura, en lo cual consiste la virtud, la cual, como facultad adquirida, nunca puede ser perfecta, porque nunca se tiene certeza apodíctica de la intención con que se ha actuado (Kant, 1968: 32). La virtud es un estado moral en que la persona tiene la intención de cumplir la ley por deber, no por voluntaria inclinación, ni siquiera por un esfuerzo no mandado y emprendido gustosamente por él mismo. Es la intención moral en la lucha, no la posesión de una pureza completa en las intenciones de la voluntad (Kant, 1968: 64-5). Dice Kant:

La más vulgar observación muestra que cuando se representa un acto de honradez realizado con independencia de toda intención de provecho en este o en otro mundo, llevado a cabo con ánimo firme bajo las mayores tentaciones de la miseria o de atractivos varios, deja muy por debajo de sí a cualquier otro acto semejante que esté afectado en lo más mínimo por un motor extraño, eleva el alma y despierta el deseo de poder hacer otro tanto. Aun niños de mediana edad sienten esta impresión y no se les debiera presentar los deberes de otra manera (Kant, 1968: 411). 
Contemplar la virtud en su verdadera figura no significa otra cosa que representar la moralidad despojada de todo lo sensible $\{\ldots\}$ Fácilmente puede cualquiera, por medio del más mínimo ensayo de su razón -con tal que no esté incapacitada para toda abstracción -convencerse de cuánto oscurece la moralidad todo lo que aparece a las inclinaciones como excitante (Kant, 1968: 426).

Si para actuar moralmente debemos hacerlo sólo por la ley moral universal abstracta, cabe preguntarse cómo se aplica esta ley a las acciones, las cuales son sensibles porque actuamos en el mundo sensible. Kant pone un cuidado extremo en mostrar que cuando se hace esa aplicación, la ley moral como principio no entra en contacto con principios sensibles. Hace falta un intermediario para esa aplicación, que Kant denomina la típica del Juicio puro práctico. En la subsunción de una acción posible para mí en el mundo de los sentidos bajo una ley pura práctica, dice, no se trata de la posibilidad de la acción como suceso en el mundo de los sentidos, cuya posibilidad pertenece al juicio teórico. Se trata de un esquema, no de un caso según leyes, sino de una ley misma, porque la determinación de la voluntad sólo por la ley, sin otro fundamento de determinación, enlaza el concepto de la causalidad con otras condiciones muy distintas de las que constituyen la conexión natural. A la ley natural, a la que están sometidos los objetos de intuición sensible, tiene que corresponder un esquema o procedimiento universal de la imaginación, que expone a priori el concepto puro del entendimiento determinado por la ley a los sentidos. Pero bajo la ley de la libertad —es decir la ley moralno condicionada sensiblemente, no puede ponerse ninguna intuición, ningún esquema para su aplicación in concreto. La ley moral no tiene más facultad de conocimiento que le proporcione aplicación a objetos de la naturaleza que el entendimiento -no la imaginación- el cual puede poner para el Juicio, debajo de una idea de la razón, no un «esquema» de la sensibilidad, sino una ley tal que puede ser expuesta in concreto en objetos de los sentidos. Es una ley de la naturaleza sólo según su forma, a la que llamamos el tipo de la ley moral (Kant, 1968: 68-9).

\section{La relación entre inclinaciones y razón práctica en Aristóteles y Tomás de Aquino}

Como vimos en la Introducción, se puede establecer un acuerdo fundamental entre Kant y Tomás de Aquino a partir del cual comenzar el debate: ambos convienen en que existe una ley moral universal que es conocida por la persona común a partir de su razón práctica. A su vez, gran parte de los elementos que se encuentran en la visión tomista de la 
razón práctico-moral son de tradición aristotélica. En efecto, siguiendo a Aristóteles, Tomás afirma que el bien y el mal de las acciones, su moralidad en términos kantianos, es determinado por la razón en su función práctica, la cual, cuando no es impedida por factores externos, es siempre recta (Aquino, 2000a: 92-93). Todo acto recibe su especie de su objeto, dice Tomás, y el bien y el mal del objeto se relacionan de por sí con la razón, según convengan o no con ella (Aquino, 2006: II, 182-184). «El bien es lo primero que se alcanza por la aprehensión de la razón práctica, ordenada a la operación» (Aquino, 2006: II, 731-733). Las primeras nociones de la moralidad son conocidas por tanto espontáneamente por la razón práctica.

De modo análogo a Kant, existe en la ética de Aristóteles y Tomás de Aquino cierta oposición entre las pasiones sensibles y la razón práctico-moral, en algunos caracteres morales, oposición que no permite a la razón exponerse en toda su rectitud. En el vicioso, el desorden habitual de las pasiones destruye los principios morales de la razón, porque está persuadido de que los deleites son buenos por sí mismos (Aquino, 2000: 392). El incontinente, por otra parte, aunque no posee esa persuasión, persigue no obstante los placeres corporales desordenadamente contra el orden que le impone su misma razón (Aquino, 2000a: 392). Estas contradicciones entre razón y sensibilidad no son sin embargo constitutivas del hombre como en Kant, sino errores individuales según Aristóteles, consecuencias de la caída original y del pecado individual según Tomás de Aquino (Aquino, 2006: I, 846-847).

El conocimiento práctico de los principios morales depende pues del carácter moral de la persona, tanto en Aristóteles como en Tomás de Aquino. El hombre virtuoso es, según Aristóteles, canon y medida de todas las cosas (Aristótles, 1985: 38; y tiene opinión correcta sobre los principios (Aristóteles, 1985: 113). El vicio, en cambio, destruye ese conocimiento (Aristóteles, 1985: 114). En consecuencia, el problema fundamental para la filosofía moral aristotélica no es, como para Kant, la justificación racional de las normas, ya que la validez moral de estas últimas se inscribe en un esquema mucho más amplio, cuyo lugar está ocupado por las virtudes morales (MacIntyre, 1987: 315), a cuya descripción Aristóteles dedica buena parte de su Ética a Nicómaco. Es a partir del ejercicio de las virtudes morales que el hombre va descubriendo las normas morales. Para Kant, en cambio, el concepto de virtud es marginal a la justificación racional de las normas (MacIntyre, 1987: 290). Si para este último la virtud es, como vimos, un cierto carácter moral que ejercita quien actúa con la intención de aplicar la ley moral, constituye sin embargo un estado en que la persona no actúa por inclinación, sino por un esfuerzo de la voluntad que vence precisamente a la inclinación. Hay 
correspondencia entre el virtuoso kantiano y el continente aristotélico y tomasiano, quien tiene concupiscencias malas y fuertes, pero no es llevado por ellas a actuar contra la razón (Aquino, 2000a: 363; Aristóteles, 1985: 103-104). Si para Aristóteles y Tomás la continencia es un carácter moral defectuoso con respecto a la virtud, para Kant es el estado moral permanente de quien ha alcanzado la virtud.

Pues bien, la teoría de la virtud moral de Aristóteles proporcionó el punto de partida de lo que MacIntyre ha llamado la «tradición clásica» de la filosofía moral (MacIntyre, 1987: 153-4). Tomás de Aquino desarrolló el tema de las virtudes morales en toda su complejidad a partir de la de Aristóteles. Se concluye de su pensamiento que en el ejercicio de las virtudes morales adquiridas el hombre alcanza la plena racionalidad moral (Aquino, 2006: I, 733-734). Tomás desarrolló una teoría de los principios morales que no se encuentra en Aristóteles, a partir del concepto de «razón natural» (Aquino, 2006: II, 710-711), conservando el esquema aristotélico de la primacía de la virtud sobre la ley. En efecto, Tomás no comienza la Suma Teológica, obra de madurez, por el problema de la justificación de la ley moral, como Kant, sino que el conocimiento de esa ley es explicado después del tratado de las virtudes y los vicios. El tratado sobre la ley ya no es aristotélico, pero, como ha señalado Rhonheimer (1994: 20-1), presupone las siguientes verdades fundamentales establecidas por el mismo Aristóteles: «el intelecto siempre está en lo correcto» (Aristóteles, 1978: 247) y «el logos siempre prescribe lo mejon» (Aristóteles, 1985: 53).

El concepto de intelecto aristotélico se prolonga y explicita más en el concepto de «razón natural» de Tomás de Aquino. Esta es una impresión de la luz divina en la inteligencia humana por medio de la cual conocemos los principios fundamentales de la ley moral natural (Aquino, 2006: II, 710-711), de manera espontánea, no raciocinante. Que sea una impresión significa que la luz divina se encuentra impresa en el ser del hombre, por lo que éste, al conocer los principios de la ley moral natural por medio de esa luz intelectual, actúa como una causa segunda (Rhonheimer, 2000a: 256, nota 2). No es por tanto que Dios ilumine en cada caso la facultad humana, porque la luz se encuentra ya impresa en su ser. Se trata de un modo natural de conocer que se encuentra en todos los hombres, sean o no cristianos. Por eso dice San Pablo en Rom 2,14: «Los gentiles que no tienen ley, cumplen naturalmente los preceptos de la ley». Esto significa que los paganos, aunque no conocen la ley revelada, conocen la ley por su razón natural, mediante la cual cada uno entiende y es consciente de lo que es bueno y de lo que es malo moralmente (Aquino, 2006: II, 710-711). 
La razón natural tiene así una realidad antropológica, es decir es parte de la naturaleza del hombre. No es una abstracción lógica, propia de los seres racionales en general a los que se refiere Kant, los cuales, a su vez, son también una abstracción. Según Tomás, cuando la razón natural práctica conoce el bien que el sujeto debe realizar, lo hace reconociendo como fin todo aquello a lo que el hombre se siente naturalmente inclinado, y como malo lo contrario (Aquino, 2006: II, 731-733). La razón práctica se encuentra inserta en la naturaleza del hombre o, lo que es lo mismo, en sus inclinaciones naturales. El orden de estas inclinaciones incluye todos los grados de ser del hombre: con todas las sustancias comparte la inclinación a conservarse en el ser, con los animales comparte la inclinación a la conjunción de los sexos y a la educación de los hijos, y con los demás hombres comparte la inclinación a buscar la verdad acerca de Dios y a vivir en sociedad (Aquino, 2006: II, 731-733). Estas inclinaciones son pues constitutivas de la esencia del hombre en cuanto sustancia, animal, y animal racional, esencia que lleva consigo la unión sustancial entre cuerpo y alma. El espectro de estas inclinaciones naturales es mucho más amplio que el de las inclinaciones naturales de la filosofía moral kantiana, las cuales se reducen a lo observable empíricamente por el hombre.

Cada una de estas inclinaciones tiene un fin que es esclarecido por la razón natural, la cual, a su vez, tiene una inclinación a la verdad. «Cualquier operación de la razón y de la voluntad surge en nosotros a partir de algo que nos es natural» (Aquino, 2006: II, 710-711), dice Tomás:

Por tanto, afirma, el hombre naturalmente quiere no sólo el objeto de la voluntad, sino también lo que conviene a las otras potencias: como el conocimiento de lo verdadero, que corresponde al entendimiento; o el ser, el vivir y otras cosas semejantes, que se refieren a la consistencia natural. Todas estas cosas están comprendidas en el objeto de la voluntad como bienes particulares (Aquino, 2006: II, 134).

La razón natural que, como vimos, es luz, ilumina o hace visibles tanto los bienes inteligibles inherentes a nuestras inclinaciones naturales como los males que se oponen a ellos, en la medida en que no es impedida por causas externas a ella (Aquino, 1952: 455-457; Rhonheimer, 2006: 365-6). En este punto Tomás sigue la doctrina aristotélica (Aristóteles, 1978: 247), según la cual el intelecto como tal, en el nivel de los principios, no puede errar y es siempre recto, aunque puede ser extraviado por los sentidos y por la voluntad que es libre para oponerse a lo que la razón le presenta como un bien (Rhonheimer, 2006: 366). También las inclinaciones naturales tomasianas encuentran un cierto correlato en la 
virtud natural aristotélica, según la cual cada uno tiene su carácter en cierto modo por naturaleza, ya que desde que nacimos somos justos, moderados, valientes y todo lo demás, aunque estos modos de ser sin la razón prudente pueden ser dañinos (Aristóteles, 1985: 100).

Ahora bien, son esas mismas inclinaciones las que constituyen a la razón natural como razón práctica, porque, como dice Tomás:

todo aquello a lo que el hombre se siente naturalmente inclinado lo aprehende la razón como bueno y, por ende, como algo que debe ser procurado, mientras que su contrario lo aprehende como mal y como algo que debe ser evitado. De aquí que el orden de los preceptos de la ley natural sea correlativo al orden de las inclinaciones naturales (Aquino, 2006: II, 731-733).

Así por ejemplo, el precepto de cuidar la propia vida es establecido por la razón natural a partir de la experiencia de la inclinación natural que el hombre comparte con todos los seres sustanciales a mantenerse en el ser. En Kant, al contrario, la persona no puede establecer el deber de cuidar la propia vida a partir de una inclinación hacia ella (Kant, 1968: 397-8), porque esa inclinación sería sólo sensible y encerraría a la persona en la búsqueda de una satisfacción individual y contingente, lejos de la universalidad de la ley moral. No es que esa inclinación sensible sea mala moralmente, como tampoco ninguna otra inclinación sensible. La voluntad es mala al elegirla como motivo de una acción (Kant, 1968: 32-3). En el individuo kantiano todas las inclinaciones son sólo sensibles y no pueden ser principios o motivos de acciones moralmente buenas. En Tomás de Aquino, en cambio, todas las inclinaciones, también las sensibles, pueden ser principios o motivos de las acciones moralmente buenas.

La razón, para pensarse a sí misma como práctica, dice Kant, tiene que hacerlo desde un punto de vista fuera de los fenómenos, en un mundo inteligible, punto de vista que no es posible bajo los influjos de la sensibilidad (Kant, 1968: 458). Según este punto de vista, la razón toma un interés inmediato en la acción, interés puro, sólo cuando la validez universal de la máxima determina la voluntad. Si la voluntad se determina por un objeto del deseo, o por un sentimiento particular del sujeto, la razón toma un interés mediato en la acción, meramente empírico, que no puede fundar la moralidad del acto (Kant, 1968: 459-60). «Si de la razón pura que piensa ese ideal separamos toda materia, esto es, todo conocimiento de los objetos, no nos quedará más que la forma, a saber: la ley práctica de la universal validez de las máximas $\{\ldots\}$ como posible causa eficiente, esto es, como causa determinante de la voluntad» (Kant, 1968: 462). 
El hombre como ser racional debe considerarse a sí mismo como «inteligencia», dice Kant, y como perteneciente al mundo inteligible, no al mundo sensible. Así tiene dos puntos de vista desde los cuales considerarse a sí mismo: el primero, en cuanto que pertenece al mundo sensible bajo leyes naturales heterónomas, y el segundo, en cuanto pertenece al mundo inteligible bajo leyes independientes de la naturaleza, no empíricas, fundadas sólo en la razón (Kant, 1968: 452). En el contexto del neokantismo Korsgaard, en la línea de interpretación de Rawls, ha afirmado que la fuerte distinción y separación realizada por Kant entre dos mundos en el hombre, el de los «noúmenos» y el de los «fenómenos», situando la moralidad sólo en el primero, no es una distinción ontológica, sino más bien una diferencia entre actividad y pasividad. Por eso la mente impone la forma de la ley en una materia o contenido dado en los mismos términos aristotélicos, lo cual es verdad tanto en la filosofía teórica como en la filosofía práctica de Kant. Nosotros creamos normas y valores imponiendo la forma de la ley sobre máximas cuyo contenido nos es dado por experiencia (González, 2003: 777).

Si analizamos más en detalle esta homologación establecida por Kosgaard entre Kant y Aristóteles, nos encontramos con unas diferencias tan importantes entre ambos filósofos que prácticamente la invalidan. Por una parte, hemos dicho que Aristóteles no se interesó en desarrollar una teoría de los principios morales o ley moral, por lo que no encontramos en su ética una forma legisladora universal, como en Kant, la cual se pueda imponer a lo dado por experiencia. Para Aristóteles, la moralidad de las acciones se le muestra al hombre virtuoso sin más (Aristóteles, 1985: 38), no a través de una norma abstracta, sino en la manera de realizar la acción (González, 2009: 106). Esto significa que la razón práctica aristotélica no es un principio o una forma pura que se pueda imponer a lo dado por experiencia, sino que posee desde un principio una dimensión orética, porque los apetitos la proveen de razones germinales para actuar (González, 2006: 110-1).

Por otra parte, dentro de la tradición aristotélica hemos visto que Tomás de Aquino desarrolló una teoría de la ley moral universal, la cual es conocida por la razón natural a partir de la experiencia. Parece más adecuado por tanto establecer la comparación recién citada de Korsgaard entre Kant y Tomás, más que entre Kant y Aristóteles. En el trasfondo de la comparación establecida por Korsgaard está la sugerencia de entender la relación entre materia y forma en el conocimiento práctico de Kant como la unión entre materia y forma en el conocimiento práctico de la tradición aristotélica. En el primer caso hablo sólo de relación porque me parece que no hay unión como en el segundo caso, lo cual hace una 
diferencia esencial entre el conocimiento práctico-moral de ambas tradiciones, y supone dos antropologías radicalmente distintas.

Según Korsgaard la moralidad, en el pensamiento de Kant, necesita materia sobre la cual trabajar, la cual proviene de la naturaleza empírica del hombre (González, 2003: 778). En efecto, para llegar a establecer, por ejemplo, una ley práctica moral según la cual no se puede negar un depósito cuyo establecimiento no pueda probarlo nadie, tengo que haber proporcionado a la razón pura práctica el contenido de una máxima mía según la cual deseo aumentar mi fortuna por todos los medios seguros, y la posibilidad de quedarme con un depósito que está en mis manos y cuyo propietario ha muerto sin dejar nada escrito acerca de él (Kant, 1968: 27-8). En otras palabras, la ley moral universal se establece en ese caso a partir de lo que Korsgaard ha denominado una «identidad práctica» empírica o contingente (González, 2003: 778), que en este caso es el deseo de apropiarse del depósito concreto que encuentro frente a mí. Nadie piensa una ley moral universal completamente en el vacío. El problema es que Kant dice que la voluntad, para observar la ley práctica universal en este caso, no puede alegar la propia inclinación, es decir la codicia, como el fundamento de su determinación, porque la inclinación, lejos de ser apta para una legislación universal, tiene que plegarse más bien a la forma de una ley universal (Kant, 1968: 28). Como dice Korsgaard interpretando a Kant, la función de la razón es legislar para el bien del todo, mientras que el deseo hace proposiciones legislativas impulsado por las necesidades e intereses empíricos de la persona. Es decir, la razón y el deseo no son propiamente rivales, sino que juegan diferentes roles funcionales (González, 2003: 778). Ahora bien, precisamente por jugar diferentes roles, razón y naturaleza son dos factores que entran en relación, pero permanecen siendo independientes el uno del otro.

De todo ello se desprende ciertamente que la inclinación no es un principio del obrar moral, como la razón, sino que debe plegarse a los dictámenes de esta última, permaneciendo en su identidad distinta, estableciéndose una relación con la razón que de ninguna manera es unión en una misma naturaleza. Aunque la razón necesite de la materia para establecer la ley práctica universal, sigue siendo una facultad que se impone a una materia que le es ajena, proveniente de la naturaleza empírica del hombre. Razón y materia son entonces principios yuxtapuestos, y sólo el primero impone la moralidad, sin tomar nada del segundo, sino sólo poniéndole ciertos límites. Este tipo de relación entre forma y materia en el conocimiento moral es enteramente extraño a Aristóteles, para quien existe una unión sustancial entre el cuerpo y el alma espiritual en el hombre y, por tanto, entre las facultades de ambas partes de la naturaleza humana. Para Kant existe una cierta oposición entre esos dos principios 
porque, como dice Korsgaard, la razón legisla para el bien del todo, mientras que el deseo propone legislar para la satisfacción de necesidades e intereses empíricos del individuo (González, 2003: 778). Esa oposición la resuelve, en el virtuoso, la razón práctica o voluntad que impone la ley universal. Según Aristóteles, por el contrario, el virtuoso, que es el prudente, conoce el universal en el mismo singular sensible (Aristóteles, 1985: 98), universal que se refiere al bien o fin de toda la naturaleza del hombre, tanto sensible como espiritual.

Tomás de Aquino prosigue la tradición del hilemorfismo práctico aristotélico, al cual perfecciona con su teoría de la razón natural y de las inclinaciones naturales del hombre. La razón natural conoce la ley moral universal, que no es para Tomás algo que se impone a lo mensurado, estableciendo límites en la actividad del hombre. Al contrario, para Tomás que algo se halle medido y regulado se debe a que participa de la medida y de la regla. No hay heterogeneidad entre lo medido y la regla. Ahora bien, todas las cosas se encuentran sometidas a la divina providencia en cuanto están medidas y reguladas por la ley eterna, es decir en cuanto bajo la impronta de esta ley se ven impulsadas a sus actos y fines propios. El hombre participa de esta providencia de un modo superior, en cuanto por su razón participa de la razón eterna, por lo que se encuentra inclinado a los actos y fines debidos. Esta participación de la ley eterna en la criatura racional es la ley natural, que es el conocimiento de los fines debidos de nuestras inclinaciones naturales por medio de la razón natural, que es luz (Aquino, 2006: II, 710-711). El hombre por tanto es capaz de conocer el deber por su razón natural, en lo que se encuentra una analogía con la razón práctica kantiana. La diferencia en esta analogía es que para Kant la razón no es natural, y se contrapone a la naturaleza del hombre aunque establezca una relación con ella.

En I-II, q.94, a.2, Tomás dice «que todo aquello a lo que el hombre se siente naturalmente inclinado lo aprehende la razón como bueno y, por ende, como algo que debe ser procurado, mientras que su contrario lo aprehende como mal y como vitando». Es decir que la razón natural aprehende los fines debidos en los fines propios de las inclinaciones naturales. La razón natural no participa de la sabiduría eterna en directo, por decirlo de algún modo, sino a través de las cosas, tal como han sido creadas y se encuentran fuera de ella. En esto se manifiesta el realismo de Tomás frente al idealismo de Kant. ¿Cómo se realiza esa aprehensión? Tomás no lo explica en ese texto. Es una de las preguntas que hay que hacerle después del predominio cultural del formalismo kantiano. Pero en otros contextos de su obra contiene suficientes explicaciones como para dar una respuesta a esa interrogante. Rhonheimer ha hecho una 
interpretación de otros textos del Aquinate para dar respuesta a esa pregunta (Rhonheimer, 2000a: 75-8).

En Tomás de Aquino las distintas facultades del hombre, tanto sensibles como intelectuales, están integradas en la persona, en la cual hay unidad sustancial entre la materia y la forma, entre el cuerpo y el alma espiritual. El juego de las facultades se sigue por tanto de esa integración entitativa. En el centro o en lo profundo de esa interacción de facultades se encuentra la voluntad, apetito intelectual cuyo objeto es el bien en común, en el cual están incluidos los fines y las perfecciones de todas las otras potencias como bienes particulares (Aquino, 2006: II, 124-125). La voluntad tiende por naturaleza a ese bien común, el cual se comporta en lo apetecible como los primeros principios de las demostraciones en lo inteligible (Aquino, 2006: II, 132-133), porque la voluntad tiende a una forma presentada por el intelecto, por lo que su objeto proporcionado es la razón de bien o el bien universal (Aquino, 2006: II, 40). Por eso las inclinaciones de cualquier parte de la naturaleza del hombre, también las sensibles como el concupiscible y el irascible, son ordenadas por la razón (Aquino, 2006: II, 733).

Ese ordenamiento no hay que entenderlo en sentido kantiano, según el cual la razón examina las proposiciones de las máximas y les impone su punto de vista a priori sin tomar nada de ellas. Hay que entenderlo más bien como una iluminación del fin de la misma inclinación por parte de la razón natural, la cual lo explicita como un bien humano. Ahora bien, sólo los objetos de las inclinaciones racionales del hombre, pertenecientes, recordemos, al tercer nivel del orden indicado en I-II, q.94, a.2, son objetos adecuados a la voluntad. Los bienes sensibles o imaginables no son proporcionados a la voluntad, pero llegan a ser su objeto en cuanto son objetivados por la razón (Aquino, 2006: II, 192) como bienes humanos, pertenecientes a la perfección de toda la persona humana. La razón natural aprehende los fines de las inclinaciones naturales, los cuales son integrados dentro del orden de la razón que los comprende como fines de la persona humana, y como un contenido que constituye a su vez un precepto de la ley natural moral al que tiende la voluntad como a su objeto. El precepto es de la razón natural práctica, y ordena realizar cierto tipo de acciones. Ese mandato no surge de la misma inclinación, sino de la moción de la voluntad y, por eso, es libre.

El precepto no es impuesto por la voluntad sobre las inclinaciones en un acto de autodeterminación respecto a ellas, como en Kant. Para establecerlo, la razón natural aprehende la finalidad que tiene la inclinación para la vida humana en su conjunto, a partir de su objeto natural, ya sea espiritual o sensible. Esto no significa que la razón se quede en la naturalidad de las inclinaciones. Lo que hace la razón es integrarlas en su 
propio orden para la perfección de la persona humana entera. Esto es así respecto a todas las inclinaciones, pero podemos verlo ahora en relación a la inclinación a la sexualidad que, por ser sensible, se acerca más al esquema kantiano. A tenor de esta inclinación, dice Tomás, «se consideran de ley natural las cosas que la naturaleza ha enseñado a todos los animales, tales como la conjunción de los sexos, la educación de los hijos y otras cosas semejantes» (Aquino, 2006: II, 731-733). La mera naturalidad de esta inclinación impulsa, en su nivel instintivo, a actos de copulación y a ciertas relaciones de pareja que en algunos animales son relativamente estables y duraderas, pero que con frecuencia faltan por completo. La procreación animal va acompañada de ciertos efectos socializadores, en la mayoría de los casos muy limitados. En el hombre, en cambio, la sexualidad, aunque está condicionada por el instinto, no es guiada por él. Esta inclinación lleva al hombre a una relación entre dos personas, un varón y una mujer, los cuales objetivan la inclinación sensible como un bien humano, dándole una nueva forma a nivel de una persona que es unión sustancial entre cuerpo y espíritu. Entonces, las relaciones surgidas entre hombre y mujer en virtud del instinto sexual, y respecto a las consecuencias del acto sexual que son los hijos, se constituyen bajo la dirección de la razón - y de la voluntad guiada por la razón-, en amor, autoentrega de una persona a la otra, fidelidad, responsabilidad procreativa, indisolubilidad de la unión. Estos no son bienes que se añaden a la sexualidad, sino que son la sexualidad misma como bien humano (Rhonheimer, 2000b: 298-301).

Ahora bien, la razón natural práctica aprehende los fines de las inclinaciones naturales espontáneamente para dirigir la acción, en el contexto del pensamiento de Tomás de Aquino. «El bien es lo primero que se alcanza por la aprehensión de la razón práctica, ordenada a la operación» (Aquino, 2006: II, 731-733). De modo análogo la razón vulgar, según Kant, tiene siempre presente la ley moral, aunque no la precise abstractamente, y la usa como criterio para sus enjuiciamientos (Kant, 1968: 403-4). Sin embargo, ese conocimiento práctico depende en Tomás, como en Aristóteles, del carácter moral de la persona. En ellos, la razón es la medida del bien y del mal en las acciones, como en Kant, pero lo es, a diferencia de Kant, en cuanto el cuerpo humano es informado por un alma espiritual, que se distingue por su racionalidad. Por eso Aristóteles, cuando explica el argumento del ergon, dice que la condición para que el hombre actúe bien es que domine la razón, y que las tendencias que no son racionales por sí mismas se ordenen de conformidad con la razón, en cuanto son capaces de participar de la razón. La virtud moral consiste en que la parte irracional esté bien dispuesta como para ser persuadida por la razón (Aristóteles, 1985: 16-18), y es así condición de la rectitud de 
esta última. Tomás coincide con Aristóteles en que la medida del obrar bueno es la razón, afirmando además que «la perversidad de la razón repugna a la naturaleza de la razón» (Aquino, 2000a: 92). Para que la razón acierte infaliblemente con el bien, basta que no se vea obstaculizada en su propia actividad judicativa - es decir en la racionalidad correspondiente a su naturaleza-, por una influencia «externa» (Rhonheimer, 2000b: 171), es decir por las pasiones y la voluntad desordenadas, no virtuosas. Una razón equivocada no es razón. Ya que Tomás ha definido la razón natural como una «luz» impresa en el alma, se puede comparar su acto con un rayo de luz, según la metáfora de la luz. La luz no se puede emplear para oscurecer. En tanto que es luz ilumina, hace visible, permite que comparezca lo escondido. Pero la luz puede ser más débil o más intensa, sus rayos pueden chocar con obstáculos, pueden ser oscurecidos, filtrados o desviados. La facultad intelectual es como una fuente de luz, y su acto como un rayo de luz. Todo lo que falsee su acto no procede de ella, sino que es un obstáculo para su propio acto (Rhonheimer, 2000b: 174).

\section{Relaciones entre antropología y ética: Kant y Tomás de Aquino}

Hemos considerado que la unión entre inclinaciones y razón práctica en Aristóteles y Tomás de Aquino, la moralidad de las acciones y las normas morales que las rigen se acoplan en una antropología metafísica. El obrar humano supone un sujeto, es decir una persona en la que hay unidad sustancial entre materia y forma, entre cuerpo y espíritu. El análisis de ese obrar tiene que hacerse en correlación con puntos de vista antropológico-metafísicos. Esto no significa que las normas que rijan la praxis moral deban deducirse de premisas antropológico-metafísicas. Significa más bien que el hombre común, en la deliberación racional de lo que debe hacer moralmente, es guiado también por las inclinaciones esenciales de la naturaleza humana y por los buenos sentimientos o virtudes morales que son racionales.

Kant tiene justamente la posición contraria. Aunque coincide con estos filósofos clásicos en que las reglas morales no se deducen de premisas antropológico-metafísicas, va mucho más allá considerando que no debe haber ningún acoplamiento de los principios morales en la antropología, ya que esta última es sólo empírica. Afirma que una metafísica de las costumbres debe estar cuidadosamente purificada de todo lo empírico, dándonos a conocer sólo lo que la razón pura puede por sí sola construir de forma a priori (Kant, 1968: 389). La filosofía moral no aprovecha ni lo más mínimo del conocimiento del hombre, es decir de la antropología, sino que le da, como a ser racional, leyes a priori (Kant, 1968: 389). 
Establece así una separación radical entre antropología y razón pura práctica, la cual no es parte de la antropología. Según Schneewind, Kant no tiene ninguna respuesta acerca de la relación entre cuerpo y espíritu - o materia y forma - en la moralidad, salvo una conjetura que expone en Träume eines Geistersehers, erläutert durch Träume der Metaphysik, publicado por primera vez en 1766 (Kant, 1968: 315-384). Esta obra del período pre-crítico de Kant es un análisis irónico de la obra de Swedenborg que lleva ese título (Schneewind, 1998: 505), la cual publicó primero de forma anónima.

Swedenborg fue un científico y teólogo-místico contemporáneo de Kant, que creía recibir visiones de Dios sobre el mundo de los espíritus que estaban en contacto con el mundo terrestre. Kant combatió esas fantasías metafísico-espiritualistas, observando que el uso de una lógica en la presentación de las pretendidas visiones espirituales no constituye ninguna garantía de que correspondan a la realidad, por no estar fundadas en la experiencia. Sin embargo, posteriormente Kant no rechazó por entero esas ideas, al menos una de esas tesis: la posibilidad de un mundo inteligible en el cual los espíritus estén en contacto y relación mutuos (Ferrater Mora, 1994: 3425-6).

En la obra pre-crítica recién mencionada, en el capítulo dos, Kant hace una exposición de lo que Swedenborg intenta demostrar acerca de la comunidad existente entre nosotros, los hombres en el mundo, y los espíritus. Termina esa exposición diciendo que él intentará explicar la constitución sistemática de la unión entre el espíritu y el mundo a partir de una observación real y aceptable, y no sólo a partir de un concepto de la naturaleza del espíritu, como lo ha hecho Swedenborg, porque esto último no es más que una hipótesis (Kant, 1968: 329-34).

En el mismo momento en que nos proponemos satisfacer nuestras necesidades con cosas externas, dice Kant, nos sentimos ligados por cierta sensación que nos hace percibir una voluntad distinta, operativa dentro de nosotros, que nos fuerza a dirigir nuestro querer hacia el bienestar de los otros, aunque frecuentemente esto sucede en contra de nuestra voluntad y con fuerte oposición contra nuestras inclinaciones egoístas. Esa voluntad distinta es la fuente de nuestros impulsos morales, los cuales nos inclinan a actuar contra el interés por sí mismo. Reconocemos entonces que somos dependientes en nuestros motivos secretos de una regla de la voluntad general, que confiere unidad moral al mundo de los seres pensantes, y lo dota de una constitución sistemática formada de acuerdo con leyes puramente espirituales. Así como la ley de gravedad de Newton gobierna las tendencias de todas las partículas materiales por una fuerza denominada «atracción», del mismo modo podemos suponer y representarnos el fenómeno de los impulsos morales en los seres pensantes como 
el efecto de una fuerza activa en virtud de la cual las naturalezas espirituales ejercen influencia unas sobre otras (Kant, 1968: 334-7).

Kant reconoce así el mundo de los espíritus a partir de la observación sobre lo que sucede en nosotros mismos. En esta explicación kantiana, realizada a la manera de Hume (Hume, 1960: xxii-xxiii), distinguimos dos modos de observación: la de la materia, de la cual se induce la ley de gravedad, y la de la propia mente. Al establecimiento de la «gravitación» de la materia, Newton llegó por medio de la observación y ciertas demostraciones matemáticas, que no quiso mezclar, según Kant, con disputas filosóficas fastidiosas acerca de la causa de esa tendencia (Kant, 1968: 335-6). Debemos suponer por tanto que en el caso del descubrimiento en nuestra mente de una voluntad general que une moralmente a todos los seres pensantes a través de su espíritu, no debemos tampoco preguntarnos por la causa de esa voluntad espiritual ni por su consistencia metafísica.

En todo caso, a partir de esos dos tipos de observación de los hechos, tanto físicos como espirituales, no se puede establecer la unión entre cuerpo y espíritu, entre materia y forma, que salvaría a Kant de su formalismo moral. En el mismo capítulo referido de Träume eines Geistersehers, afirma que la representación que el alma humana tiene de sí misma como espíritu, por medio de una intuición inmaterial, a través de la cual está en relación con seres de la misma naturaleza, es muy distinta a las representaciones que tiene el alma humana cuando es consciente de sí misma como «ser humano», a través de imágenes extraídas de las impresiones recibidas por los órganos del cuerpo, las cuales sólo pueden referirse a las cosas materiales. De acuerdo con esto, si bien es verdad que hay un solo sujeto el cual es simultáneamente miembro del mundo visible y del mundo invisible, no hay, sin embargo, una y la misma persona para las representaciones de un mundo y del otro, debido a la manera distinta de constituirse las ideas relativas a ambos mundos. Así, lo que yo pienso como espíritu no es recordado por mí como ser humano, y, al contrario, mi estado como ser humano no entra en absoluto en la representación de mí mismo como espíritu (Kant, 1968: 337-8).

Es verdad que todas estas afirmaciones kantianas son establecidas como respuesta a un análisis irónico de la obra de Swedenborg, por lo que el talante con que la escribe es más bien jocoso. Sin embargo, como dice el mismo Schneewind, es natural que leamos esas páginas a la luz de lo que conocemos de las obras maduras de Kant, y que percibamos que el grado al cual estas obras maduras llevan sus primeras especulaciones es sorprendente (Schneewind, 1998: 506). Al comienzo de esta sección vimos con qué radicalidad afirma Kant en la Grundlegung que la filosofía moral no aprovecha ni lo más mínimo del conocimiento del hombre, es 
decir de la antropología, sino que le da, como a ser racional, leyes a priori (Schneewind, 1998: 19). Porque la antropología se refiere, según Kant, al «ser humano», y no al hombre como espíritu.

En la tradición aristotélico-tomista encontramos, en cambio, una antropología metafísica que abarca al hombre según ambas dimensiones, corpórea y espiritual, lo que nos permite explicarnos el conocimiento de la ley moral universal desde principios afines al hombre como unión sustancial entre cuerpo y alma espiritual y, por tanto, desde las facultades de ambas partes de la naturaleza humana. En la base del conocimiento de la moralidad de las acciones y de la ley moral hay en Aristóteles y en Tomás de Aquino una antropología de la virtud moral en que se manifiesta esa unión sustancial, enteramente desconocida por Kant. Seguramente por eso el Tratado de las virtudes en general y el Tratado de los vicios y pecados se encuentran en Tomás de Aquino antes que el Tratado de la ley en general.

La virtud no es, en ese contexto, nada más que fuerza de la voluntad o racionalidad. No consiste en someterse al imperativo categórico, o en tener consciencia del deber o estar resuelto a hacer el bien. Es la armonía interna del hombre y de todas sus tendencias con la razón. La virtud moral es la integración de lo sensible-corporal en la lógica del espíritu (Rhonheimer 2000b, 204-9). Con ella, los apetitos sensibles se conforman con la razón, y participan de algún modo de ella, llegando a ser principios de las acciones morales (Aquino, 2006: II, 445-446). Porque la virtud de la parte apetitiva es cierta disposición firmemente impresa por la razón en ella (Aquino, 2000b: 171-185). Por eso no existe una oposición entre la acción virtuosa y la acción placentera como en Kant. Dice Aristóteles que «ni siquiera es bueno el que no se complace en las acciones buenas, y nadie llamará justo al que no se complace en la práctica de la justicia, ni libre al que no se goza en las acciones liberales, e igualmente en todo lo demás. Si esto es así, las acciones de acuerdo con la virtud serán por sí mismas agradables» (Aristóteles, 1985: 11).

\section{REFERENCIAS}

-Aquino, T. de (1952). Suma contra Gentiles. Madrid: B.A.C.

-Aquino, T. de (1998). De Veritate, 16 y 17 (A. M. González, Trad.). Pamplona: Cuadernos del Anuario Filosófico.

-Aquino, T. de (2000a). Comentario de la Ética a Nicómaco de Aristóteles. (A. Mallea, Trad.) Pamplona: Eunsa.

-Aquino, T. de (2000b). Cuestión disputada sobre las virtudes en general. (L. Corso de Estrada, Trad.). Pamplona: Eunsa. 
-Aquino, T. de (2001). De Veritate. Cuestión 22 (J. F. Sellés, Trad.). Pamplona: Cuadernos del Anuario Filosófico.

-Aquino, T. de (2006). Suma de Teologia (4 Vols.). Madrid: B.A.C.

-Aristóteles (1978). Acerca del alma, Madrid, Gredos.

-Aristóteles (1985). Ética a Nicómaco, Madrid, Centro de Estudios Públicos.

-Delbos, V. (1969). La philosophie pratique de Kant. París, Presss Universitaires de France.

-Edwards, J. (2000). Self-love, Anthropology, and Universal Benevolence in Kant's Metaphysics of Morals. The Review of Metaphysics, LIII(4), 887-914.

-Edwards, J. \& Brook, S. (2000). Egoism and Formalism in the Development of Kant's Philosophy. Kant-Studien, 91(4), 411-432.

-Ferrater Mora, J. (1994). Diccionario de Filosofía (T. IV). Barcelona: Ariel.

-González, A.M. (2003). Ethics at the Intersection of Kant and Aristotle. An Inteview with Christine M. Korsgaard. Anuario Filosófico, 36(3), 99-112.

-González, A.M. (1999). El Faktum de la razón. Pamplona: Cuadernos del Anuario Filosófico.

-González, A.M. (2009). Aristotle and Kant on Practical Reason. Acta Philosophica, 18, 99-112.

-Hume, D. (1960). A Treatise of Human Nature. Oxford: The Clarendon Press.

-Kant, I. (1968). Kants Werke. Akademie Textausgabe. Berlin: Walter de Gruyter \& Co.

-Kant, I. (2003). Theoretical Philosophy 1755-1770. The Cambridge Edition of the Works of Immanuel Kant. Cambridge, Mass.: Cambridge University Press.

-Kant, I. (1946). Fundamentación de la metafísica de las costumbres. (M. García Morente, Trad.). Madrid: Espasa-Calpe.

-Kant, I. (1969). La religión dentro de los límites de la mera razón. (F. Martínez Marzoa, Trad.). Madrid: Alianza Editorial.

-Kant, I. (1975). Crítica de la razón práctica. (M. García Morente, Trad.). Madrid: Espasa-Calpe.

-MacIntyre, A. (1987). Tras la virtud. Barcelona: Crítica.

-MacIntyre, A. (1990). Three Rival Versions of Moral Enquiry. London: Duckworth.

-Maritain, J. (1995). La Philosophie Morale: examen historique et critique des grands systèmes, en J.-R. Maritain, Oewures Complètes. Fribourg: Editions Universitaires.

-Paton, H. J. (1948). The Categorical Imperative. Chicago: University of Chicago Press.

-Rhonheimer, M. (2000). Ley natural y razón práctica. Pamplona: Eunsa.

-Rhonheimer, M. (1994). Praktische Vernunft und Vernunftigkeit der Praxis. Berlin: Akademie Verlag.

-Rhonheimer, M. (2006). Nature as Reason: A Thomistic Theory of the Natural Law. Studies in Christian Ethics, 19(3), 357-378.

-Rhonheimer, M. (2000). La perspectiva de la moral. Madrid: Rialp.

-Rodríguez Luño, A. (2004). Ética General. Pamplona: Eunsa. 
-Schneewind, J. B. (1998). The Invention of Autonomy. Cambridge: Cambridge University Press.

Sumario: Introducción; 1. La relación entre las inclinaciones sensibles y la razón pura práctica en Kant: los principios del deber moral; 2. La relación entre inclinaciones y razón práctica en Aristóteles y Tomás de Aquino; 3. Relación entre antropología y ética: Kant y Tomás de Aquino; Referencias. 